\title{
El decir de la hechura: una lectura de la estética piñeriana en dos cuentos fríos
}

\author{
María Virginia González \\ UNIVERSIDAD NACIONAL DE LA PAMPA·Vicky_bono@yahoo.com.ar
}

Profesora en Letras por la Universidad Nacional de La Pampa. Actualmente está terminando tesis doctoral sobre la narrativa escrita por mujeres cubanas a finales del siglo XX. Forma parte del Grupo de Estudios Caribeños (ILHUBA) dirigido por la Dra. Celina Manzoni. Entre las publicaciones recientes se encuentra "La transgresión del ensayo: Ella escribía poscrítica de Margarita Mateo Palmer". En Salto, Graciela (ed.). Memorias del silencio: literaturas en el Caribe y Centroamérica. Buenos Aires: Corregidor, 2010.

RECIBIDO: 31 DE ENERO DE 2013

ACEPTADO: 15 DE MARZO DE 2013

Resumen: Autor de célebres poemas, cuentos y novelas extraños, renombradas obras de teatro y lúcidos ensayos, Virgilio Piñera (Cárdenas 1912-La Habana 1979) resulta aún hoy un escritor controvertido no suficientemente divulgado o, por lo menos, no tanto como lo merecería su vasta y rica producción literaria. En el campo cultural cubano su estética ha provocado diversas reacciones y durante años estuvo condenada al silencio aunque en la actualidad, la crítica reconoce su impronta en la generación que comienza a publicar a partir de los años ochenta. En estas páginas me interesa reflexionar sobre la travesía literaria que ofrece el cuerpo de la escritura piñeriana. Para esto me centraré en la lectura de dos cuentos que permiten rastrear cómo se hacen y deshacen las líneas que dibujan el itinerario de una estética que pone en entredicho otras escrituras mientras bordea los contornos del silencio.

Palabras Clave: Literatura, Cuba, cuento, Virgilio Piñera
Abstract: Author of famous poems, uncommon short stories and novels, renowned plays and lucid essays, Virgilio Piñera (Cárdenas 1912 - La Habana 1979) results still today a controversial writer not enough disclosed or, at least, not as much as his extensive and wealthy literary production. In the Cuban cultural sphere, his aesthetics has caused different reactions, and for years it was condemned to silence. But today, criticism recognizes its mark on the generation that begins publishing from the eighties.

In these pages, I want to reflect on the literary journey that offers the body of Piñera's writing. For this purpose, I will focus on reading two stories that allow tracking how make and break the lines that draw the itinerary of this aesthetic which challenges other scriptures, whereas skirting the edges of silence.

Key Words: Literature, Cuba, short stories, Virgilio Piñera 
"El autor estima que la vida no premia ni castiga, no condena ni salva, o, para ser más exactos, no alcanza a discernir esas complicadas categorías. Sólo puede decir que vive; que no se le exija que califique sus actos, que les dé un valor cualquiera o que espere una justificación al final de sus días. En realidad dejamos correr la pluma entusiasmados. De pronto las palabras, las letras se entremezclan, se confunden; acabamos por no entender nada, recaemos en la infancia, parecemos niños con caramelos en las bocas. Y entonces espontáneo, ruidoso, brota ese misterioso balbuceo:

ba, ba, ba, ba..."

VIRGILIO PIÑERA

En las últimas décadas del siglo XX, mientras Cuba atraviesa profundos cambios sociales, políticos y económicos, en el campo cultural se produce un proceso de apertura y de rechazo al dogmatismo imperante en la década del setenta. ${ }^{1}$ Este proceso deriva en la constitución de diversos grupos de literatos, cineastas, artistas plásticos que, a partir de su actuación en el campo de la cultura, cuestionan el sistema de valores establecidos desde la

\footnotetext{
${ }^{1}$ La crisis sociopolítica se inicia en 1980 con la ocupación de la embajada del Perú y posterior salida de más de 125.000 cubanos por el puerto del Mariel. Luego se suma el "Proceso de Rectificación de Errores y Tendencias Negativas" en 1986; los errores y tendencias estaban asociados tanto a las estrategias económicas que habían sido aprobadas por el $1^{\circ}$ Congreso del Partido Comunista Cubano y funcionado por medio de dos planes quinquenales, como a la "pérdida de efectividad" en el funcionamiento del partido, las organizaciones de masas y los órganos de poder popular. Los principios básicos fueron continuar la orientación marxista-leninista de la revolución, ratificar el papel dirigente del Partido Comunista Cubano como partido único y rechazar el mercado y la propiedad privada (Mesa-Lago, 1993). La crisis se acentúa en 1989 con la desaparición del socialismo en Europa del Este y la posterior desintegración de la Unión Soviética, sus socios comerciales durante más de tres décadas. La desaparición del campo socialista significó un nuevo reacomodamiento para Cuba y la rectificación fue sustituida por un conjunto de reformas de gran alcance que abarcó los órdenes institucional y económico, el llamado "Período Especial en Tiempos de Paz", expresión con la que el discurso oficial ha nombrado tanto a la crisis como a las reformas. Esta situación se acentuó a partir de las restricciones económicas provocadas por el recrudecimiento del bloqueo de EE.UU. A partir de estos hechos, a comienzos de los noventa, Cuba empieza a atravesar una situación de emergencia económica que produjo el deterioro en todas las instancias de la vida, llegando a evidenciarse retrocesos en sectores prioritarios como la alimentación y el empleo y poniendo en peligro la salud y la educación, consideradas las dos grandes conquistas de la Revolución (Holgado Fernández, 2000; Jennissen, 2001; Nuñez Sarmiento, 2001; Vega Quintana, 2003).
} 
esfera estatal. ${ }^{2}$ Con respecto al campo literario, la crítica observa cambios que son el resultado de todas las transformaciones que ha sufrido la sociedad desde fines de los ochenta (Redonet Cook, 1993; López Sacha, 1996; Fornet, 2006; Huertas, 1993). En la antología Los últimos serán los primeros (1993), Salvador Redonet Cook presenta una muestra de la escritura de los narradores de este período, a los que denominó, indistintamente, los "novísimos", los "iconoclastas" y "la tercera generación de la Revolución". Este crítico tiene un papel central en la institución y consolidación del grupo que constituye la primera promoción de escritores y escritoras nacidos y formados luego del triunfo de la Revolución: Rolando Sánchez Mejías, Ernesto Santana, Alberto Garrandés, Roberto Urías, Ronaldo Menéndez, Ena Lucía Portela, Daniel Díaz Mantilla, Pedro de Jesús López, Verónica Pérez Konina, por citar algunos nombres. Es a la producción literaria de esta generación de escritores a la que alude indirectamente Antonio José Ponte en las palabras pronunciadas en el Coloquio que homenajeó en 1992 a Virgilio Piñera:

No sé si ustedes son capaces de enunciar sus sueños, tal vez no tengan nombres para ellos o andemos escasos de sueños. Dudo que un sueño nuestro pueda coincidir con el que los origenistas alentaron, sueño o espejismo. Las pesadillas, sin embargo, son en mucho las mismas y Virgilio Piñera supo dar con ellas. Absurdo, nada, vacío, sinsentido: acostumbran llamarla con algunos de esos nombres. Situaciones que continúan repitiéndose, pesadillas que no asustan tanto desde que podemos saltar gritando en la anagnórisis: "Si esto es Virgilio puro, caballeros". Así mismo nos legó un repertorio de frases que decir en las guaguas o las paradas por donde no pasan, en las casas de huéspedes y el bar, la esquina y el patio de butacas, la antesala del dentista y la funeraria, el parque y la carnicería, la barbería y la cola del pan, la crónica social y policíaca, el secreteo y el grito del solar. Como personajes suyos hablamos en Piñera clásico, hemos caído en la lengua de Virgilio. (Ponte, 1992)

Esta afirmación de Ponte contrasta (o redime) con la soledad y el aislamiento en el que vivió sus últimos años Virgilio Piñera (Cárdenas 1912-La Habana 1979), años que van aproximadamente desde 1965 hasta su muerte. ${ }^{3}$ Durante la Cuba anterior a 1959, Piñera

\footnotetext{
${ }^{2}$ Esta situación cultural se concretó en varios proyectos alternativos a la cultura oficial: en las artes escénicas, el grupo Ballet Teatro de La Habana y el teatro Obstáculo; en la literatura, el movimiento de poesía joven y el proyecto Paideia; en la plástica, los proyectos Arte Calle, Hacer y Castillo de la Fuerza. Todos estos grupos tenían en común la inmersión crítica en la realidad sociopolítica del país, el desafío al universo de valores dominantes y la búsqueda de espacios no institucionales para desarrollar sus actividades. Para un extenso desarrollo del tema, consultar Mosquera (1991), Cámara (1991) y Bobes (2000).

${ }^{3}$ Estos años se enmarcan en lo que se conoce como el "quinquenio gris" de la cultura cubana, aunque algunos críticos hablan del decenio negro. Con respecto a los debates actuales sobre el "quinquenio gris", se produjo un ciclo de conferencias y debates, muchos de los cuales circulan en
} 
se exilió casi diez años en Buenos Aires donde publica la novela La carne de René en Siglo XXI y Cuentos fríos en Losada y regresa a Cuba a fines de 1958. Luego Guillermo Cabrera Infante lo invita a participar en Lunes de Revolución, suplemento literario del periódico Revolución, que pertenecía al Movimiento 26 de Julio. Cuando en 1961 cerraron este suplemento cultural, pasó a ser traductor de francés en la Editora Nacional durante los años de fuerte homofobia de la Revolución ${ }^{4}$.

En la cita de Ponte se lee la enumeración de escenarios ligados a la nimiedad de lo cotidiano donde se despliega y construye la llamada lengua popular - y la afirmación final de la "caída" en la lengua de Virgilio que pone en evidencia, no sin ironía, el deslizamiento producido desde las alturas gnósticas del sueño lezamiano hasta el repertorio léxico y semiológico del "Piñera clásico". Deslizamiento producido por la nueva generación de escritores y escritoras que se sienten deudores de la estética piñeriana y que permiten hablar del "fenómeno Piñera", por nombrar de alguna manera a la recuperación de la obra de este escritor que se produce en el campo literario cubano de las últimas décadas del siglo XX. En este sentido, Damaris Calderón (1994) considera que las características más salientes de esta generación -el uso de la parodia, la ironía, la revisión de la épica, la aparición de un discurso gay, la desmitificación del arcadismo social, geográfico, poéticotienen una fuerte impronta piñeriana. También señala la desconfianza de estos escritores hacia la palabra porque no siempre puede aprehender realidades más vastas; desconfianza

internet. Para una síntesis interesante de la cuestión ver la conferencia de Ambrosio Fornet titulada "El quinquenio gris: revisando el término" (2006).

4 En el artículo "La muerte en vida", Antón Arrufat, discípulo de Piñera, refiere anécdotas vividas durante los años en que algunos escritores fueron silenciados: "En los años del setenta, calificados por Piñera de muerte civil, la burocracia de la década nos había configurado en esa 'extraña latitud' del ser: la muerte en vida. Nos impuso que muriéramos como escritores y continuáramos viviendo como disciplinados ciudadanos. Dar muerte al ser que nos otorgaba la escritura y existir con el que nos otorgaba el Estado, exigencia casi metafísica en una sociedad que se proponía el materialismo, era imposible de cumplir. Tras la orden, la burocracia, dando por hecho esta imposibilidad, tomo las necesarias medidas estatales para llevarla a la práctica. Nuestros libros dejaron de publicarse, los publicados fueron recogidos de las librerías y subrepticiamente retirados de los estantes de las bibliotecas públicas. Las piezas teatrales que habíamos escrito desaparecieron de los escenarios. Nuestros nombres dejaron de pronunciarse en conferencias y clases universitarias, se borraron de las antologías y de las historias de la literatura cubanas compuestas en esa década funesta. No sólo estábamos muertos en vida: parecíamos no haber nacido ni haber escrito nunca. Las nuevas generaciones fueron educadas en el desprecio a cuanto habíamos hecho o en su ignorancia. Fuimos sacados de nuestros empleos y enviados a trabajar donde nadie nos conociera, en bibliotecas alejadas de la ciudad, imprentas de textos escolares y fundiciones de acero. Piñera se convirtió, por decisión de un funcionario, en un traductor de literatura africana de lengua francesa" (Arrufat, 1999). 
que también se traslada hacia los símbolos y emblemas cubanos tradicionales como la palma, el paisaje, la patria.

Luego de años de silenciamiento de la obra de Piñera, hoy se reconoce su marca en la generación que comienza a publicar a partir de los años ochenta. ${ }_{\mathrm{C}}^{5}$ Por qué se revaloriza Piñera en este contexto? ¿Qué elementos de su estética recogen los escritores actuales? ¿Por qué retoman a Piñera y reniegan del barroquismo de Lezama o Carpentier? (sin entrar a ahondar por ello en si Piñera es o no barroco, problema que también ha sido abordado por diferentes estudios críticos) ${ }^{6}{ }_{\mathrm{C}}$ Ofrece Piñera una salida al insularismo paradisíaco de Lezama-Carpentier-Vitier? Estos han sido algunos de los interrogantes que la crítica ha intentado responder. Otro lugar común ha sido afirmar que Piñera resistió los discursos utópicos y totalizantes para elegir, en cambio, los reductos irracionales a través del uso de la ironía y el humor negro; en esta línea se ubican quienes hablan del nihilismo y del absurdo como características centrales de su obra. ${ }^{7}$ En reiteradas ocasiones también se ha señalado la presencia del cuerpo en su narrativa; a este tema ha vuelto una y otra vez la crítica para señalar sus antecedentes y vinculaciones (Sade) o para caracterizar el uso de cuerpo humano con sus partes, sus funciones y movimientos, es decir, el cuerpo humano con su materialidad concreta que, según advierte Diana Álvarez Amel (1999), sirve para expresar nociones culturales acerca de cómo funcionan las relaciones en la sociedad. ${ }^{8}$

${ }^{5}$ Un ejemplo es el cuento "El viejo, el asesino y yo" (2000) de Ena Lucía Portela (La Habana, 1972) en el que advierto un vínculo entre el final de este cuento y la temática y la estética de "La caída" de Piñera. En una instancia posterior de investigación, analizaré como dialogan estos relatos. ${ }^{6}$ Uno de quienes tienen esta postura es José Bianco, en el prólogo a El que vino a salvarme. Caracteriza el barroco en la obra de Piñera a partir de la presencia de visiones goyescas o quevedianas: "mujeres que no pueden besarse porque antes se comieron los labios, hombres que se prestan a devorarse entre sí, en cadena, haciendo las veces de Acteón y los perros, o que no vacilan en saltarse los ojos para evitar la perniciosa seducción de una cara" (Bianco 1970: 8). Señala que Piñera es un hombre barroco y que por lo tanto siente el consabido desengaño barroco ante el destino del hombre: "Escritor barroco, lo manifiesta intelectualmente. $\mathrm{Al}$ absurdo del mundo responde con el humorismo" (Bianco, 1970: 10). También retoma esta postura Mónica Bernabé en "El cielo del paladar" donde señala que en las modestas tertulias virgilianas es posible advertir una "actitud barroca. Aquella que Leo Spitzer señaló en los «crueles desenmascaradores de la tragedia de la carne flaca». La extravagancia de Virgilio Piñera consiste en llevar la nada a su «punto de máxima saturación» y convertirla en una realización total" (Bernabé, 2001: 24).

${ }^{7}$ Es Cintio Vitier quien inaugura esta lectura de Piñera. Por el contrario, Riné Leal (2002) y Diana Álvarez Amel (1999) sostienen que hablar de nihilismo en la obra de Piñera ha sido una forma de manifestar recelo a su producción y condenarla al silenciamiento.

${ }^{8}$ En los cuentos de Virgilio Piñera aparecen cuerpos humanos en estado incompleto -cojos, ciegos, personajes con cuerpos petrificados-, o cuerpos humanos fragmentados - en "La caída", "El casamiento". Para Diana Álvarez Amel, la falta de las partes del cuerpo "se incorpora al relato como elemento narrativo para entender las relaciones sociales en las que están inmersos estos personajes. En los textos de ficción la falta de partes del cuerpo humano no se entiende en su aspecto personal; 
En estas páginas me interesa centrarme en esta problemática del mundo piñeriano pero dejaré de lado el cuerpo como materialidad concreta para reflexionar sobre la travesía literaria que ofrece el cuerpo de la escritura. Para esto me centraré en la lectura de dos cuentos que permiten rastrear cómo se hacen y deshacen las líneas que dibujan ese itinerario: "La caída" y "El álbum". La elección se debe a razones de diversa índole: "La caída" ocupa el primer lugar en la serie de los Cuentos fríos, posición que no es casual ni aleatoria ya que supone un acto deliberado del autor y, también, porque en esa serie es posible considerar que cada cuento anticipa al siguiente -anticipación que es temática y estética - y en el primero resulta posible leer una presentación de su proyecto literario que luego se plasma en el resto del libro. A esta afirmación se vincula también la elección de "El álbum" porque aquí se puede leer una puesta en acto de la poética piñeriana y de su concepción de la literatura, en otras palabras, lo que se pone en juego en el relato es una querella sobre la ficción misma.

\section{Una estética del despojo.}

En el cuento corto "La caída", la historia es muy simple: dos alpinistas caen desde la cima de una montaña de tres mil pies de altura y es uno de ellos el que narra en primera persona cómo en el despeñamiento -causado por una ligera alteración de los movimientos - luchan por salvar una parte de sus cuerpos: los ojos de uno y la barba del otro. Con una prosa lacónica y a través de una narración lineal, el narrador toma al lector de la mano para conducirlo según su voluntad y condenarlo a una lectura denotativa del texto. $^{9}$

el conflicto de los personajes no es íntimo, sino social". En este sentido, realiza una interesante lectura del cuento "La carne" y concluye en que "El cuento de Piñera desmantela la rigidez de la relación, inseparable en La carne, entre el 'adentro' del cuerpo humano y el 'afuera' social. El cuento constituye una fábula sobre la destrucción, lo que ancla la narración en fundamentos éticos. La carne es una parábola de la autodestrucción colectiva en pos de la satisfacción personal que autoconsume a los miembros de un pueblo, a fin de cuentas, irredento." En La carne de René, Piñera lleva al paroxismo esta temática al narrar las desventuras de un hijo que al cumplir los veinte años es obligado por su padre a sacrificarse al servicio del dolor. Esta es su primera novela, publicada en 1952 por la editorial Losada de Buenos Aires, luego siguieron Pequeñas maniobras en 1963 y Presiones y diamantes en 1966.

${ }^{9}$ En "La protohistoria de la frialdad", Teresa Cristófani Barreto señala que "los cuentos de Piñera, bien mirados, son fríos no solamente porque, como quiere su autor, «se limitan a exponer los puros hechos». Son fríos porque se han enfriado, porque se rehúsan a probar nuevamente el erotismo retórico, en la acepción que Severo Sarduy da al término, porque han conquistado la denotación. Su narrador ha dejado de decir, ha silenciado, se ha hecho frígido. Piñera partió de un estilo expresamente lezamiano, cuando todavía echaba palabras a borbotones sobre el papel y su decir era caliente; cuando otorgaba a Lezama la tarea de destruir cuantos lugares comunes encontrara en sus 
Como ya señalé, resulta importante considerar la posición que ocupa en los Cuentos fríos ya que es aquí donde se configuran los elementos centrales de su estética. En primer lugar, el cuento erige el absurdo como técnica de la construcción del relato pero no por el uso de la estética del absurdo (que podemos pensar en el teatro de Eugène Ionesco, Samuel Beckett, con tramas con atmósferas oníricas, diálogos repetitivos, etc.) sino por la visión del mundo generada por la ilogicidad de una voz en primera persona que va relatando cómo se desmiembra el cuerpo de sí mismo y de su compañero en una caída al abismo. ${ }^{10}$ Como señala Riné Leal (2002), el absurdo de Piñera no es un estilo, una manera, un modo o una moda, por el contrario, es un instrumento de indagación, una forma de analizar la verdadera realidad, sólo que esa realidad es tan paradójica, tan negativa que únicamente a través del absurdo interno puede ser comprendida y comunicada. El hecho - la caída e inminente (y nunca dicha) muerte- pierde tragicidad y, en cambio, se desmitifica a partir de la comicidad que significa salvar una parte del cuerpo. Esta operación pone en primer plano el detalle: la minuciosa descripción de la caída del personaje preocupado por salvar los ojos y la barba. Y, en tanto detalles, remiten a una totalidad: la materialidad del cuerpo humano con todos sus miembros. Piñera rechaza la idea del "todo", del "entero", de la totalidad y, en cambio, ubica en escena la parte, el resto y es a partir de estos elementos que se configura un sistema de producción de sentido. Omar Calabrese (1999) señala que la operación de detallar supone un mecanismo implícito: producir detalles depende de una acción explícita de un sujeto -en este caso, el narrador en primera persona- sobre un objeto -el cuerpo suyo y el de su compañero- y de que entero y parte están copresentes. Este sujeto es el que se hace presente a través de la mirada para describir los hechos, el espacio y el tiempo en el que se desarrolla la acción. De este modo, la mirada se traslada como una cámara cinematográfica que "en vivo" enfoca los hechos tal cual van sucediendo o, mejor dicho, tal como los percibe el narrador a través de los intersticios que dejan las manos de su compañero sobre sus propios ojos, unas manos que oculta y vela la visión de la totalidad. El efecto estético que logra este relato es, justamente, la desdramatización de la caída y de lo no dicho: la muerte del sujeto. Entonces, la comicidad que puede generar este efecto de desdramatización a partir del intento fructífero de salvar las partes, se puede leer

papeles literarios, para finalmente alcanzar su registro absolutamente original, sus textos fríos" (Cristófani Barreto, 1999).

${ }^{10}$ Para un análisis del absurdo en los cuentos de Piñera, ver el artículo "Virgilio Piñera and the Short store of the Absurd" de Read G. Gilgen. Allí desarrolla y ejemplifica las diferentes estrategias que le permiten destruir cualquier vestigio de orden: "grotesque and often cruel distortions of reality; a deemphasis of plot, dramatic conflict, and carácter motivation; the use of exaggerated and pseudos-dramatic language; and an orientation toward satirically black humor" (Gilgen, 1980: 354). 
por su reverso: ya no resulta cómico sino que aparece la deshumanización por la mutilación y la desintegración y ante esto, la angustia del sujeto.

Como dejé esbozado, la de Piñera se erige como una literatura de los resquicios, de las grietas. "Miré a través del ligerísimo intersticio que dejaban los dedos de mi compañero" (Piñera, 1964: 12), señala el narrador mientras describe cómo el cuerpo del otro y el suyo propio se van desmembrando: su compañero pierde las piernas, la oreja izquierda, el codo derecho, los testículos y la nariz; él, las piernas, la parte superior del tórax, la columna vertebral, la ceja izquierda, la oreja izquierda y la yugular. "Pero no es nada en comparación con lo que vino después" (Piñera, 1964: 12), afirma el narrador y, sin embargo, se introduce un elemento de nula coherencia para el marco lógico previsible para ese enunciado porque la enumeración de las pérdidas concluye para nombrar lo que resta: las manos de ambos, la barba de uno, los ojos del otro, es decir, lo que permanece a esta altura del despeñamiento se concentra en las partes a preservar y el medio para hacerlo. Finalmente, en un final epifánico -el verde del "césped de la llanura", "resplandeciente", "gloria"- yacen impertérritos los ojos y la barba.

Aunque epifánico, este final resulta antiheroico. Ya en la elección del título, se rompe con la heroicidad que supondría la hazaña de escalar una montaña porque, además de la clara alusión bíblica, toda caída implica un descuido, una torpeza, un error. Desde las primeras líneas el narrador señala que "Habíamos escalado ya la montaña de tres mil pies de altura. No para enterrar en su cima la botella ni tampoco para plantar la bandera de los alpinistas denodados" (Piñera, 1964: 11). Cuando se produce el error involuntario, los personajes caen inexorablemente -y sin dramatismo - al abismo. En el final del relato, no triunfa la solidaridad sino la autosalvación: "viendo a mis ojos huérfanos de todo amparo, debo confesar que para eterna, memorable vergüenza mía, retiré mis manos de su hermosa barba gris a fin de protegerlos de todo impacto" (Piñera, 1964: 13). No hay historia edificante ni sentimental porque sus personajes tampoco se erigen como héroes ni como construcciones admirables. Por el contrario, en la narrativa piñeriana la mayoría de los personajes pertenece al grupo de los marginados sociales -cojos, maltrechos, condenados a muerte, frustrados, la gorda de carnes opulentas- o arquetipos que, como tales, no tienen nombres que los distingan sino que recurre al uso de los genéricos -en este cuento son "alpinistas".

Literatura que narra desde los intersticios, que se centra en el detalle y que no dice o no nombra ante la imposibilidad impuesta por la palabra y como respuesta ante el desasosiego que provoca el mundo. En este caso, lo que no se nombra es la muerte, tópico que en muchas narraciones aparece como el final esperable. Por el contrario, en el cuento se utiliza la estrategia de la elipsis y, de este modo, se convierte en un no-final: sin llantos, sin caos, sin trascendencia, la muerte no se nombra y, en cambio, cuando cae, el sujeto constata 
que se salva la parte, el detalle, y es desde allí desde donde comienza a narrar. En este sentido es posible decir que el final es liberador ya que el sujeto alcanza el clímax al final de la caída -no en la cima de la montaña - cuando sólo lo constituye (y está constituido por) los ojos: el narrador convertido en un sujeto fragmentado observa impávido la barba de su compañero. La clave constructiva de la estética piñeriana la encontramos, entonces, en el final de la historia: la narración se hace desde un sujeto que se va fragmentando y justamente esta fragmentación da lugar a la narración, en tanto, de no suceder la caída no habría habido cuento.

\section{El quehacer literario: un anestésico contra la podredumbre.}

En "El álbum" se narran los hechos que desencadena el espectáculo en torno a la exhibición de un libro de fotografías de "la gorda opulenta" a los huéspedes de una pensión ${ }^{11}$ (digo espectáculo porque en la hechura de la historia se ponen en funcionamiento muchos recursos del discurso teatral). ${ }^{12}$ Un narrador en tercera persona presenta el marco espacio temporal de la obra y luego da paso a un narrador en primera persona -el nuevo huésped- quien conduce el resto de la narración e introduce los diálogos que entabla con los demás personajes con aclaraciones de entonaciones, gestualidades y movimientos. La historia gira en torno a tres personajes: el portero, quien en forma clandestina vende los lugares para asistir a la exhibición; "la dama de carnes opulentas" que cuenta la historias de las fotos del álbum y cuyo relato puede ocupar una semana completa o más porque cada circunstancia convoca una serie infinita de historias relacionadas; y el huésped novato que narra en primera persona la historia y en el que es posible advertir un alter ego del autor no sólo por lo sugestivo de su actividad -trabajo como lector - sino también por las posiciones que adopta a lo largo de la historia, por

\footnotetext{
${ }^{11}$ Todas las citas pertenecen a la edición de Unión citada en la bibliografía. En el cuento observo elementos de la estética del cine expresionista alemán pero no los desarrollaré aquí debido a que el análisis se centra en otro eje.

12 Como es sabido, Piñera fue un excelso escritor de obras de teatro. Esta historia también la presentó como obra teatral con el mismo nombre. No he podido constatar cuál fue elaborada primero. En su análisis del absurdo en los cuentos de Piñera, Read Gilgen sostiene que "The principal differences lie in the realization of the grotesque distortions of reality necessary to comunicate such a notion: the short store must create this effect verbally, while the theater relies heavily on scenery, costuming, lighting, mime, madcapping, and other purely visual techniques" (Gilgen, 1980: 149). Sin embargo, en este cuento se fusionan los recursos del teatro con los de la narrativa, aspectos que se perciben en el análisis que realizo.
} 
ejemplo, como veremos más adelante, en los diálogos que velan una discusión en torno a la literatura. ${ }^{13}$

En el cuento se desoculta el acto procesal de la escritura y también, se desarticulan y ponen en jaque otras estéticas. Esto se puede leer a partir de una pregunta central que es la que estructura el texto y que la realiza el narrador al portero: "Pero dígame: ¿qué interés real puede tener la exposición de un álbum de fotografías?" (Piñera 1964: 54). ${ }^{14}$ Lo que sigue no es una respuesta esperable o, por lo menos, no en términos de logicidad entendida como el razonamiento que rige la razón o el sentido común- porque lo que oficia de tal es una extensa lista de preguntas y respuestas de aparente sinsentido en la que se puede leer una disquisición en torno a la literatura y, por metonimia, al arte en general:

'CSe ha fijado usted -dijo el viejo, tomándome por las muñecas y haciéndome colocar ante la puerta del cuarto, que estaba rematada por un arco de vidrios multicolores-en la belleza de esos vidrios? Son de la época colonial. Cuando nada tengo que hacer, salgo por las calles a buscar puertas con vidrios de colores. Parece que hay cierta gente que también los busca'. 'Sí -dije—es una agradable operación salir con el solo objeto de buscar vidrios de colores. Pero dígame: podrías distinguir entre una vidriera antigua y una imitación moderna?'. 'Mi tío usaba un dentífrico de los que ya no se ven hoy en día; murió con el supremo placer de una dentadura impecable'. 'Sí, sí, eso es, una dentadura impecable; pero mire usted: sólo me quedan algunos dientes del arco superior $-\mathrm{y}$ me le eché encima con la boca abierta-. ¿Querría usted darme la fórmula de ese dentífrico?'. 'Hace diez años que vengo burlando a la encargada del piso. Todos los días la veo desnuda; si me hubiera pillado, ¡adiós, portero!' ‘ ¿ $\mathrm{Y}$ qué tiene eso de excepcional?'. 'Ya no puedo de noche comer mi pan con lechón; el estómago no me acompaña' '¿'Y por qué no se compra un digestivo?' ‘'Sabía usted que nunca he usado medias?'. 'A sus años, jeso es una imprudencia! iNo ve que estamos rodeados de humedad?’. ‘Qué fea está esa mesa; yo tengo por ahí una latica de esmalte. Ya verá usted cómo le va a quedar.... ‘Pero es que el niño de al lado se pasa toda la noche gritando’. ‘'Eh, qué le pasa!... -gritó furioso el viejo-, ¿está tocado? Yo no le he hablado de ningún niño. Le digo muy claramente que tengo una latica de esmalte'. 'Pero es que ese niño no me deja dormir en toda la noche' (Piñera, 1964: 54-55).

La conversación se corta por el sonido de un timbre que los vuelve a la "realidad". Como señalé, una primera lectura del diálogo o, mejor dicho, del no-diálogo, nos remite a

${ }^{13}$ La puntualidad es un rasgo del personaje que se repite varias veces en el cuento. Al mismo tiempo, es una característica de la personalidad del autor a la que hacen referencia muchos de los que lo conocieron, por ejemplo, Antón Arrufat en "La muerte en vida".

${ }^{14}$ La cursiva me pertenece. 
un juego de palabras provocado por la ilogicidad de una serie de preguntas y respuestas sin sentido. Sin embargo, esta es la clave para descifrar el texto ya que se debate sobre qué (y cómo) debe versar la literatura o, mejor dicho, se dirime una clásica discusión: el problema de forma y contenido. La pregunta que desencadena el juego remite a dos problemas centrales: el de la representación y el de su incidencia en la "realidad", por llamarla de alguna manera. La respuesta (o las respuestas) ponen en escena una serie de confrontaciones entre dos estéticas: la del portero -el cancerbero de la Literatura, representada por el álbum-y la del narrador (alter ego del autor) -el "nuevo huésped" que vive de la literatura. La primera serie refiere a los vidrios de colores como referencia a la realidad y plantea el problema de la belleza, del original y de la copia. La segunda, con la referencia a la boca, a los dientes y al dentífrico remiten al lugar donde se procesa la palabra y discurre sobre la existencia de la fórmula que logre el texto perfecto -sostenida por el portero que remite a su antepasado - y la respuesta irónica del narrador que muestra descarnadamente su propia carencia y clama que le sea dada la fórmula perfecta. Desde la tercera a la sexta serie de preguntas y respuestas se puede leer el problema del tema: copiar lo que vemos (la vecina desnuda), embellecerlo (la mesita estropeada) u optar por lo cotidiano (la comida, las medias). Justamente es aquí donde se interrumpe el diálogo (o el no diálogo): el portero insiste en la visión estética de la mesa y el narrador no lo oye o no le responde abstraído por el recuerdo de los gritos de un niño en la noche.

El niño aparece en escena en el párrafo siguiente cuando se presentan ante el narrador la mulata y su hijo. Aquí se vuelve a poner en primer plano el problema de la representación, esta vez en el discurso de la mulata que describe minuciosamente su sombrero de bodas que "era un modelito del invierno pasado" y que gracias a las habilidosas manos de sus tías "lo reformaron que nadie lo hubiera conocido!" porque "compramos lentejuelas y ellas le bordaron la copa imitando unas mariposas que estaban expuestas en la vidriera del "Arte"” (Piñera, 1954: 56). ${ }^{15}$ Las palabras de la mulata ponen el centro de atención en la problemática del original y de la copia -la habilidad de unas manos que logran emularlo ocultando la imitación - pero también remiten al Arte consagrado y a sus emuladores. En el diálogo que sigue reaparece el problema de cómo representar lo "real":

\begin{abstract}
Alfonso se mató de un tiro en la boca delante de mí. Eh, cqué le parece? Muy bonito: pegarse un tiro en la boca. Usted, ¿está soñando? ¿Por qué no grita? Yo grité cuando lo vi lleno de sangre. ¡A ver, grite! Cuándo él se pegó el tiro yo grité así (aquí distendió la boca pero sin dejar escapar un grito). ¿Lo ve? ¿Lo está
\end{abstract}

\footnotetext{
${ }^{15}$ La mulata es la generadora de historias, la que otorga sentido a la narración: cuando se está por caer el relato, es quien comienza a engendrar historias. Además, el relato de la mulata está construido por una suma de frases hechas y mezcla de temas.
} 
viendo? Yo abrí la boca; la volví a cerrar; la volví a abrir y grité otra vez. ¿Se da

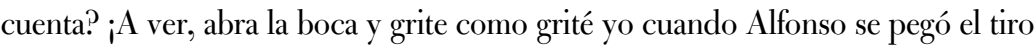
en la boca! (Piñera, 1964: 59).

la mulata insiste en reproducir el hecho tal cual fue y lograr el mismo efecto en el narrador-personaje que oficia de receptor de su relato. La inmutabilidad del narrador, su negativa a gritar y la elección del silencio ponen el foco de atención sobre las elecciones de la estética piñeriana: la discusión en torno a la estética se plantea no sólo por un problema de temas (¿de qué hablar?) sino por la forma, dicho de otro modo, el problema no es si se habla de un hecho trágico (en este caso, el suicidio) sino, cómo se habla de eso.

Si nos centramos en el punto de vista del narrador protagonista, en los párrafos precedentes es posible observar cómo se dirime el modo en que se debe contar a partir de la puesta en jaque de otros modos, es decir, la respuesta en torno a cómo (y a sobre qué) narrar se configura a partir de cómo no narrar. ${ }^{16}$ De este modo, se desarticulan estéticas que se erigen como verdades absolutas: la avalada por el portero -que metonímicamente representa a la "gorda de carnes opulentas" porque es quien legitima y comercializa el espectáculo- y en un plano secundario - por el espacio más acotado que ocupa en el texto- se termina de configurar la estética que se cuestiona en el discurso de la mulata.

Esta estética se configura en torno a la imagen del álbum de fotografías, es decir, la literatura pensada como imágenes que copian la "realidad". Cuando el álbum hace su aparición en escena, el narrador señala que

un silencio repentino me hizo bajar la vista. Este silencio lo había provocado la dama del álbum que acababa de hacer su aparición. La seguía un hombre de pequeña estatura y regordete, que llevaba en sus brazos, como los sacerdotes llevan la Sagrada Forma en el cojín de terciopelo, un álbum inmenso de fotografías (Piñera, 1964: 64).17

La descripción de la escena parodia la pompa en torno a la literatura consagrada. ${ }^{18}$ Aquí, contar es "traer a colación" (Piñera, 1964: 71) y con esta estrategia el escritor representado por "la dama de carnes opulentas" - crea y recrea la historia a partir de sucesivos encadenamientos de descripciones de detalles: "Ahora voy a tener a bien explicar

\footnotetext{
${ }^{16}$ En otra instancia de investigación, la teoría de Derrida resultaría de suma utilidad para leer este aspecto.

${ }^{17}$ La cursiva me pertenece.

18 También se observan resabios del artepurismo que brega por una literatura aislada de lo económico y de lo político: "Claro que la dama ignoraba el negocio del portero: inmediatamente habría suspendido sus festejadas y frecuentes exhibiciones del álbum" (Piñera, 1964: 49). En esta lectura, el portero sería aquel que negocia con el arte, mientras que los vecinos con sus diferentes clases sociales, aludirían a los distintos tipos de público.
} 
la historia particular del resto de los invitados, además de una minuciosa descripción de sus respectivas 'toilettes'. Vamos a empezar por la señora del gobernador" (Piñera, 1964: 70) y de este modo se parodian las narraciones realistas al estilo Balzac donde el paroxismo de los detalles generan la imposibilidad de narrar: "Finalmente se añade a la masa partes iguales de vainilla, canela y esencia de limón" (Piñera, 1964: 73). Olegario, el esposo de "la gorda de carnes opulentas" otorga veracidad a los hechos narrados porque permite contrastarlos con los efectivamente sucedidos: "ella lo sienta a su lado para que en el momento que, ladeando su cabeza, le diga: '¿'No es verdad, Olegario?’, o ‘¿Te acuerdas, Olegario?, él, sin pronunciar una palabra mueva su cabeza afirmativamente"' (Piñera, 1964: 51-52).

En este espectáculo también es posible rastrear la ficcionalización del campo literario, los agentes que lo componen así como las leyes que rigen su funcionamiento. Leyes que como tales resultan plausibles de romper aunque quienes se someten a ellas, las conocen y las respetan:

Una vez que el portero anunciaba que los mejores puestos estaban ya vendidos, ninguno de los huéspedes humildes hubiera osado ocuparlos. Claro que hubieran podido sentarse en cualquiera de ellos, pero el temor de provocar un escándalo que habría ofendido con toda seguridad a la dueña del álbum les hacía soportar esta suprema humillación que toda pureza impone (Piñera, 1964: 50).

Por otra parte, el cuento realiza un guiño irónico a la estética lezamiana. Un elemento que permite realizar esta lectura es la presencia de "la gorda de carnes opulentas" portadora de esta literatura porque, como es de público conocimiento, Lezama y Piñera eran conocidos como "el gordo y el flaco". En el relato también se puede observar este contraste de estéticas en la siguiente descripción del marco que encuadra la exhibición del álbum:

El comedor presentaba, como se dice, un «golpe de vista magnífico». Las sillas habían sido colocadas en semicírculo, y aquello parecía un pequeño anfiteatro, cerrado al fondo por falsas columnas de cemento estucado que eran parte de la recargada ornamentación del comedor; de columna a columna corrían festones y hayas, hojas y frutas de piedra, todo pintado de un delicioso y ridículo color amarillo. En las cuatro paredes del comedor se veían cuadros colgados con los tradicionales temas de cenas y convites; otros representaban inmensos fruteros llenos de zapotes, piñas, mangos, y también frutas de otros países, como la manzana y la pera, el melocotón y los dátiles. Una gran lámpara, cuyos ocho brazos eran otros tantos tritones, colgaba del centro del comedor. Yo me había perdido en la contemplación de sus bronces (cagados de moscas) y de sus lágrimas (más cagadas todavía) cuando un silencio repentino me hizo bajar la vista (Piñera, 1964: 63). 
En la descripción se hace presente la exuberancia del barroco lezamiano, con sus festines de comidas, los espacios recargados, fastuosos, metonimias de la voluptuosidad verbal que construye el discurso. Ante esta profusión de imágenes, materiales y formas, el narrador fija la vista en el detalle de mal gusto e insiste en esa visión: la caca de las moscas. ${ }^{19}$ Del mismo modo que en el cuento anterior, el narrador focaliza la atención en el detalle, el resto, que en este caso es doblemente despreciable. En la estética representada por el álbum, el detalle es la excusa para generar el encadenamiento de extensas descripciones que engendran historias. La parodia de esta literatura se logra porque se desoculta la construcción de un hecho usual como es mirar un álbum de fotografías: el marco en el que se desarrolla y la repetitividad del acto produce la saturación de la narración y convierte el simple acto en un ritual. ${ }^{20}$ Ante tanta proliferación, el narrador opta por otra función del detalle ya que fija la atención en lo que no se nombra porque rompe con el buen gusto para, con pocas palabras - palabras afiladas, palabras silenciosas-, crear otra forma que permita comenzar a narrar.

\section{Algunas reflexiones finales (o $\mathrm{d}$ se puede enfriar el texto piñeriano?)}

Dijo Piñera, refiriéndose a sí mismo:

Soy hombre de pocas palabras y todos mis esfuerzos en la vida van encaminados a la mudez perpetua. Hay cosas que terminan por obra y arte, tanto que perdemos el hilo....No se puede vivir encogido todo el tiempo...nunca como ahora un hombre se parecía menos a otro hombre; la comunicación resultaba tan precaria que cada vez más las palabras querían decir menos y ya se notaba el temor de unos y otros a aventurarse en los abismos de una conversación. ${ }^{21}$

Ante la imposibilidad (y el sin sentido) de decir, su literatura se convierte, entonces, en un balbuceo que linda los bordes del silencio. En los cuentos analizados, es un sujeto escindido el que balbucea: en "La caída" es la fragmentación del sujeto lo que da lugar a la narración, en tanto, de no suceder la caída no habría habido cuento, mientras que en "El álbum" el sujeto que narra en algunas ocasiones opta por el silencio y, en otras, construye su discurso a partir de la puesta en duda de la palabra de otros personajes.

En su lúcido ensayo, Antonio José Ponte dice de Piñera que "Escribía negando. Escritura reactiva como ciertos preparados químicos. Tuvo tan clara conciencia de otras

\footnotetext{
${ }^{19}$ En Cuba, la estética de lo cursi aparece con la vanguardia, por ejemplo, en "La indagación del choteo" de Jorge Manach.

${ }^{20}$ Esto también se puede analizar en el cuentos el "El conflicto". Un interesante análisis de este cuento realiza Marcela Zanin (2001).

${ }^{21}$ Palabras de Virgilio extraídas del sitio web Una broma colosal
} 
voces que vino a completar. Escribió para dotar a la literatura de algo que le estaba faltando y él echaba de menos.

Piñera erigió su estética con los relatos triviales, con la emergencia de los lugares comunes, con el antiheroísmo de sus personajes, con la desintegración de la razón. De esta forma rompió con la lógica imperante en su tiempo y, sin embargo, en la actualidad hace eco en muchos escritores cubanos que publican desde las últimas décadas del siglo XX. Tal vez esta operación de recuperación de la obra y de la estética piñeriana se vincula con que su elección del detalle o del fragmento marca una época de ruptura de la totalidad (Calabrese, 1999)

Y esta es la preferencia de los escritores (y lectores) actuales. En este sentido, la lectura de Piñera permite advertir que escribió para un público que no espera moralinas ni catarsis, pero tampoco para "lectores ávidos de ejercicios de interpretación" (Zanin, 2001). Entonces, los lectores esperables son aquellos que se dejan sumergir y balancear en la hechura de una escritura que es el resultado de una pluma entusiasmada en la que las palabras, y las letras se entremezclan para terminar confundidas provocando como resultado que "acabamos por no entender nada" y, por eso la solución es recaer en el balbuceo de la infancia, como dice Piñera en la cita recogida en el epígrafe que da inicio a este trabajo. Sin embargo, detrás de ese balbuceo, de esas historias que rompen con la lógica esperada, se percibe el desasosiego que causan las desventuras humanas.

Ante esta propuesta cabe preguntarse por el sentido de su arts poética. Una vez más creo que la respuesta la da el propio escritor cuando en "Notas sobre la vieja y la nueva generación", advierte que

\footnotetext{
Nuestra generación se caracterizó por un total desapego de la política. Nos pusimos a la defensiva (...) Pensamos con toda honestidad (y uno puede pensar en términos de honestidad y al mismo tiempo resultar deshonesto) que mezclarnos en la vida política sería tanto como contaminarnos con su pestilencia (...) Depositamos entonces nuestra fe en realidades tales como la literatura, lo Bello, lo Noble, lo Bueno, que por una rara paradoja eran, al mismo tiempo, tan solo abstracciones (...) Por huir de una realidad atroz contribuíamos sin percatarnos de ello, a perpetuarla (...) Todo ello nos fue haciendo ver la vida de la nación sub especie literaturae (...) A nosotros mismos sólo nos importaba la vida y el quehacer literario por sí mismos, y más que eso, nos encantaba (Leal, 2002: X).
}

Estas palabras remiten a la generación que dio vida a la revista Orígenes en un contexto histórico-político marcado por la impronta de la dictadura de Machado (19241933) y la de Fulgencio Batista (1933-1944, 1952-1959). Es este contexto estético-político el que incide en el germen de la estética piñeriana que lejos está de ser nihilista sino que es un fino tamiz que no se despega de la acuciante realidad. 
Tanta perplejidad provocó su estética que aún hoy su obra reviste cierto silencio de parte de la crítica. Silencio que algunos explican a través de cuestiones ideológicas ligadas a las características del campo cultural cubano y otros al titubeo que todavía provoca el estilo revulsivo de un escritor que dificulta todo intento de definición y clasificación que procure enfriar la productividad de su obra. 


\section{Bibliografia citada}

Álvarez Amell, Diana. "La carne: la política de la destrucción del cuerpo en la narrativa de Virgilio Piñera". La Habana Elegante (2002).

Arrufat, Antón. "La muerte en vida". Servicio de documentación de la Universidad de Brasil (1999).

Bernabé, Mónica, Ponte, Antonio José y Zanin, Marcela (2001). El abrigo de aire. Ensayos sobre literatura cubana. Buenos Aires: Beatriz Viterbo Editora.

Bianco, José (1970). "Prólogo". Piñera, Virgilio. El que vino a salvarme. Buenos Aires: Sudamericana: 7-19.

Bobes, Velia Cecilia (2000). Los laberintos de la imaginación: repertorio simbólico, identidades y actores del cambio social en Cuba. México: El Colegio de México.

Calabrese, Omar (1999). "Detalle y fragmento". La era neobarroca. Madrid: Cátedra: 84105.

Calderón, Damaris. "Virgilio Piñera: una poética para los años 80". Servicio de documentación de la Universidad de Brasil(1999).

Cámara, Madeline (1991). "Adiós a los ochenta: ajuste de cuentas con la joven literatura cubana". Plural, 228 México: 66-72.

Cristófani Barreto, Teresa. "La poética silenciada de Virgilio Piñera". Unión. Revista de Literatura y Arte. 8, 25 (1996): 16-21.

Cristófani Barreto, Teresa. "La protohistoria de la frialdad". Servicio de documentación de la Universidad de Brasil (1999).

Fornet, Jorge (2006). Los nuevos paradigmas de la escritura: prólogo narrativo al siglo XXI.

La Habana: Letras Cubanas.

Fowler, Víctor (1998). La maldición: una historia del placer como conquista. La Habana: Letras Cubanas.

Gilgen, Read G. "Virgilio Piñera and the Short store of the Absurd". Hispanía 63/2 (1980): 348-355.

Leal, Riné (2002). "Introducción”. Piñera, Virgilio. Teatro completo. La Habana: Letras Cubanas: V-XXXIII

López Sacha, Francisco (comp.) (1996). La isla contada: el cuento contemporáneo en Cuba. Donostia: Tercera Prensa.

Mosquera, Gerardo "Los hijos de Guillermo Tell". Plural 238 (1991): 60-63. México.

Piñera, Virgilio (1964). "La caída”. Cuentos. La Habana: UNIÓN: 11-13.

Piñera, Virgilio (1964). "El álbum". Cuentos. La Habana: UNIÓN: 49-73. 
María Virginia González

Ponte, Antonio (1992). "La lengua de Virgilio". Dossier de Virgilio Piñera, Diario de Poesía. Servicio de documentación de la Universidad de Brasil (1999).

Portela, Ena Lucía (2000). El viejo, el asesino y yo. La Habana: Letras Cubanas.

Redonet Cook, Salvador (ed.) (1993). Los últimos serán los primeros. La Habana: Letras Cubanas. 